\title{
Correction to: Digital Transformation of Identity in the Age of Artificial Intelligence
}

\section{Correction to:}

K. Shibuya, Digital Transformation of Identity

in the Age of Artificial Intelligence, https://doi.org/10.1007/978-981-15-2248-2

The original version of the book was inadvertently published with incorrect Eq. 7.1 in Chapter 7, and a reference was mistakenly omitted in the Appendix section. These errors have now been corrected as given below,

1. Eq. 7.1 in Chapter 7 has been corrected as

$$
x_{1}(t+1)=\frac{r_{1} x_{1}(t)\left(1-x_{1}(t)\right)+a r_{2} x_{2}(t)\left(1-x_{2}(t)\right)}{1+a}
$$

2. The reference Shibuya, K (2009) has been included in the reference section in the Appendix.

Shibuya, K. (2009). An examination of computational model of interpersonal mental health. In IEEE the 3rd International Conference on Bioinformatics and Biomedical Engineering(iCBBE 2009), Environmental Pollution and Public Health (EPPH2009) Special Track, Psychological Health Special Session, CD-ROM Format. IEEE Press. 